\title{
Fortalecimento da microeconomia por meio da alimentação escolar
}

\author{
Strengthening the local economy through school meals \\ Fortalecimiento de la economía local a través de comidas escolares
}

Recebido: 05/11/2021 | Revisado: 1211/2021 | Aceito: 16/11/2021 | Publicado: 26/11/2021

\author{
Antônio Carlos Estender \\ ORCID: https://orcid.org/0000-0002-0547-1077 \\ Universidade Paulista, Brasil \\ E-mail: estender@uol.com.br \\ Oduvaldo Vendrametto \\ ORCID: https://orcid.org/0000-0003-2430-6138 \\ Universidade Paulista, Brasil \\ E-mail: oduvaldov@gmail.com \\ Luciana Melo \\ ORCID: https://orcid.org/0000-0002-2275-743X \\ Universidade Federal de São Paulo, Brasil \\ E-mail: lueduciat@yahoo.com.br
}

\begin{abstract}
Resumo
A alimentação exerce papel fundamental na vida do ser humano, este trabalho tem como objetivo entender a alimentação escolar via compras governamentais e o aumento da renda dos agricultores familiares, contribuindo para fortalecer a microeconomia do município. $\mathrm{O}$ artigo foi elaborado por meio de estudo de caso da Associação dos Produtores Rurais da Microbacia Hidrográfica do Rio Branco (AMIBRA) do município de Itanhaém - SP, onde foram realizadas entrevistas de natureza exploratória e qualitativa junto aos agentes econômicos da região, possibilitando a coleta de dados e de informações. Diante do exposto, a colaboração mais relevante foi a constatação de que as compras governamentais, quando adquiridas na própria cidade, podem ser uma nova forma de comercialização dos produtos agrícolas o que resulta no retorno de investimentos ao município e gera empregos e renda que fomenta a economia local. A expansão da diversificação e da quantidade de alimentos produzidos pelos agricultores para a alimentação escolar no munícipio fomentaria a economia e melhoraria a renda da comunidade.
\end{abstract}

Palavras-chave: Alimentação escolar; Desenvolvimento econômico; Produção de alimentos; Renda.

\begin{abstract}
Food plays a fundamental role in the life of the human being, this work aims to understand school feeding via government purchases and the increase in the income of family farmers, contributing to strengthen the microeconomy of the municipality. The article was elaborated by means of a case study in the Rural Producers Association of the Micro watershed do Rio Branco (AMIBRA) in the municipality of Itanhaém - SP, where interviews of an exploratory and qualitative nature were carried out with the economic agents of the region, enabling the collection of data and information. In view of the above, the most relevant contribution was the finding that government purchases can be a new way of marketing agricultural products, which would result in the return of investments to the municipality and generate income that would boost the local economy. The expansion of the diversification and quantity of food produced by farmers for school meals in the municipality would foster the economy and improve the income of the community.
\end{abstract}

Keywords: School feeding; Economic development; Food production; Income.

\section{Resumen}

La alimentación juega un papel fundamental en la vida de los seres humanos, este trabajo tiene como objetivo entender la alimentación escolar a través de las compras del gobierno y el aumento de los ingresos de los agricultores familiares, contribuyendo a fortalecer la microeconomía del municipio. El artículo fue elaborado a través de un estudio de caso en la Asociación de Productores Rurales de la Cuenca del Río Branco (AMIBRA) en el municipio de Itanhaém - SP, donde se realizaron entrevistas de carácter exploratorio y cualitativo con los agentes económicos de la región, lo que permitió la recolección de datos e informaciones. En vista de lo anterior, la colaboración más relevante fue la constatación de que las compras gubernamentales pueden ser una nueva forma de comercializar los productos agrícolas, lo que redundaría en el retorno de las inversiones al municipio y generaría ingresos que fomentarían la economía local. La ampliación de la diversificación y la cantidad de alimentos producidos por los agricultores para las comidas escolares del municipio fomentaría la economía y mejoraría los ingresos de la comunidad.

Palabras clave: Alimentación escolar; Desarrollo económico; Producción de alimentos; Renta. 


\section{Introdução}

A economia local se caracteriza pelo processo de desenvolvimento econômico e os protagonistas são o governo, as associações, comunidades e o comércio local. A alimentação escolar é importante para o desenvolvimento dos pequenos municípios e do fortalecimento da economia e quando realizada com o estímulo à geração de renda familiar tende a fomentar as economias locais, possibilitando a diversificação produtiva e o aumento de renda dos agentes envolvidos. A alimentação escolar no Brasil foi marcada pelo desrespeito aos hábitos alimentares regionais, pela prática de padronização alimentar, pelo favorecimento a grupos econômicos em detrimento dos agricultores familiares.

Os agentes econômicos são pessoas de natureza física ou jurídica que, através de suas ações, contribuem para o funcionamento do sistema econômico. O governo que, por sua vez, inclui todas as organizações, que direta ou indiretamente, estão sob o controle do Estado, nas suas esferas federais, estaduais e municipais; as associações/empresas que são unidades encarregadas de organizar as documentações necessárias junto aos produtores para as compras governamentais e também comercializar bens e serviços, e as comunidades que incluem todos os indivíduos de um grupo e suas unidades familiares que possuem o papel de produtores e consumidores que adquirem os mais diversos tipos de bens e serviços, objetivando o atendimento de suas necessidades. Com o propósito de implementar as políticas públicas locais para a comunidade, os agentes econômicos devem comprar uns dos outros na região, gerando maiores vendas e compras e assim fortalecer a microeconomia, a agricultura familiar e o próprio município.

O fator que impulsionou o processo de compras governamentais foi a criação da Lei no 11.947/2009 que além de atender uma demanda antiga dos movimentos sociais ligados à agricultura familiar, contemplou a valorização da produção agrícola local, orgânica e advinda das pequenas propriedades, com essa política podemos analisar alguns pontos como: a efetivação da geração de emprego e renda para a população e para as comunidades locais, em virtude da manutenção dos recursos do Fundo Nacional de Desenvolvimento da Educação (FNDE) no município.

A diversificação dos gêneros alimentícios que passaram a ser produzidos nas propriedades rurais, contribuindo tanto para ampliar a renda, como para melhorar a alimentação do agricultor; o estímulo à cooperação, incluindo a criação de associações e cooperativas de agricultores; a busca por novos espaços de comercialização dos alimentos, como feiras e abastecimento de supermercados locais e o resgate da cultura alimentar regional. Brasil (2012a).

Este trabalho tem como objetivo entender a alimentação escolar via compras governamentais e o aumento da renda dos agricultores familiares, contribuindo para alavancar a economia do município. É importante salientar que a alimentação escolar não se baseia apenas em observar a quantidade de alunos, mas, também os gastos públicos com a compra de alimentos no munícipio. O Brasil tem sido exemplo em relação aos programas de alimentação escolar, devido a sua efetividade, no campo da geração de renda e da melhoria da alimentação escolar, estimulada pela lei 11947/2009 que também prevê que no mínimo, 30\% dos recursos do Programa Nacional de Alimentação Escolar (PNAE) (Brasil, 2012a) sejam utilizados para a compra direta de alimentos provenientes da agricultura familiar, o que permite a aproximação entre a produção e o consumo por meio da transferência de recursos diretamente aos agricultores, impactando positivamente a economia local.

\section{Metodologia}

Para a investigação dessa temática, empregou-se o estudo de caso e documental com abordagem qualitativa. Foram utilizados dados bibliográficos, documentos oficiais e legislações para contextualizar o panorama da alimentação escolar e as compras governamentais relativas ao Programa Nacional de Alimentação Escolar.

O método escolhido foi o estudo de caso, que segundo Yin (2014), pode ser utilizado na investigação dos fenômenos da realidade, abrangendo conhecimentos teóricos e incluindo abordagens específicas à coleta e análise de dados. A principal fonte de dados da pesquisa é o ambiente natural onde foi realizada, a pesquisa de campo consistiu na observação de fatos e 
fenômenos da maneira que ocorrem espontaneamente, na coleta de dados a eles referentes e no registro de dados relevantes para analisá-los.

O estudo foi aplicado na cidade de Itanhaém (SP). A pesquisa foi realizada com agricultores familiares da Associação dos Produtores Rurais da Microbacia Hidrográfica do Rio Branco (AMIBRA) do município de Itanhaém - SP, que realizam a entrega de gêneros alimentícios para o PNAE. Os efeitos do desenvolvimento econômico, social e local, com a alimentação escolar, influenciam a geração de renda para os agentes econômicos PNAE (2018). O objetivo desse artigo é entender a alimentação escolar via compras governamentais e o aumento da renda dos agricultores familiares, contribuindo para fortalecer a microeconomia do município, favorecendo o envolvimento comunitário no sistema de produção e contribuindo para alavancar a microeconomia do munícipio, tendo como base o Programa Nacional de Alimentação Escolar (PNAE).

A coleta de dados foi realizada no Banco de Alimentos de Itanhaém, com o propósito de analisar a relação entre o fortalecimento da economia, a geração de renda e a alimentação escolar com a comercialização de alimentos dos produtores locais, em um período de 12 meses. A população estudada é composta por agricultores familiares da Associação dos Produtores Rurais da Bacia Microbacia Hidrográfica do Rio Branco (AMIBRA) de Itanhaém e região. A coleta de dados e avaliação sistêmica ocorreu de forma espontânea ao longo do processo a partir de pesquisa qualitativa com observação participante e da condução de entrevistas semiestruturadas com a comunidade e agentes locais para conhecer a relação entre o fortalecimento da alimentação escolar e a geração de renda. A realização das entrevistas semiestruturadas aconteceu entre junho de 2020 e junho de 2021 com os representantes públicos locais e agricultores., (2017). Os dados coletados foram compilados em um banco de dados eletrônico do programa Microsoft Excel e a partir daí foi possível estruturar e entender o fortalecimento da economia local, por meio do incentivo da produção de alimentos para a alimentação escolar.

Foi elaborado um diagnóstico participativo por meio de visitas à prefeitura e foram realizadas entrevistas com os representantes da secretaria da agricultura, educação e da coordenação da alimentação escolar, como também visitas in loco aos agricultores familiares e seus representantes, nesse diagnóstico foi proposto um protocolo de pesquisa sobre o fomento da economia por meio da alimentação escolar. Observou-se, durante as reuniões e entrevistas, que facilitar e construir o acesso dos agentes econômicos às compras públicas estabelece relações de compreensão entre eles e a comunidade, favorecendo o entendimento sobre o ciclo econômico e fomentando a microeconomia, pois todos participam efetivamente do fornecimento de alimentos e de bens e serviços. A pesquisa foi realizada com o propósito de conseguir informações acerca da geração de renda com a produção de alimentos voltados para a alimentação escolar e do conhecimento sobre o envolvimento dos agentes econômicos, objetivando obter informações com o intuito de descobrir fenômenos ou relações entre eles (LAKATOS; MARCONI, 1991).

\section{Referencial teórico}

\subsection{Alimentação Escolar}

A alimentação escolar (Belot \& James, 2011; Christel \& Michael, 2005; Condon, Crepinsek, \& Fox, 2009; França et al., 2018; Taras, 2005) e programas de alimentação escolar (Carnevalli, 2017; Chauhan, 2015; Jomaa, McDonnell, \& Probart, 2011; Kristjansson et al., 2016; López-Olmedo et al., 2018; McEwan, 2013; Nogueira et al., 2016) têm atraído o interesse dos agentes econômicos e dos pesquisadores, porém sabe-se pouco sobre o impacto da alimentação escolar para o fomento econômico local, para educação e para capacidade de gerar renda nas comunidades. A alimentação escolar tem sido adotada em vários países ao redor do mundo, especialmente em países em desenvolvimento, para promover a segurança alimentar. Mesmo em países mais desenvolvidos, prevenir a fome e os efeitos da fome é um propósito fundamental dos programas de alimentação escolar. Brasil (2012a). A alimentação escolar deve dialogar com outros setores relacionados, como por exemplo a agricultura, a economia local, o governo e a assistência social. Esse caráter multidisciplinar é que vai ampliar as possibilidades 
de retornos sociais, geração de renda e fomento da economia. Alguns destes retornos podem ser claramente previstos como: i) a exigência que a aquisição dos alimentos seja feita localmente, o que fixa os recursos na região, possibilitando a geração de renda local; ii) a priorização de uma alimentação saudável, o que contribui para melhorar a qualidade de vida; e, iii) fortalecimento da economia local e o aumento da produção, o que fortalece a geração de renda.

No Brasil a alimentação escolar existe a mais de 70 anos, porém o financiamento para apoiar programas de alimentação escolar foram estabelecidos pela Constituição em 1988. A alimentação escolar é financiada por recursos das contribuições sociais e outros recursos orçamentários. Para a implementação local da alimentação escolar é necessário observar o Fundo Nacional de Desenvolvimento da Educação (FNDE), autarquia criada pela Lei Federal n ${ }^{\circ}$ 5.537, de 1968, que é responsável pela execução de políticas educacionais do Ministério da Educação - MEC, tendo como missão prestar assistência técnica e financeira aos estados e municípios, como forma de contribuir para a implementação de parcela das ações educacionais, Mészáros (2011).

Os programas de alimentação pública devem ser financiados e implementados pelo governo local, como, por exemplo, aconteceu no Brasil, onde a preocupação com alimentação escolar começou na época do Estado Novo, no governo de Getúlio Vargas, responsável pela grande onda de industrialização do país. O PNAE tem sua origem nessa época, no início da década de 40, quando o então Instituto de Nutrição defendia a proposta de o Governo Federal oferecer alimentação aos estudantes. (GLEWWE; 2005; TRICHES; 2010). O Programa Nacional de Alimentação Escolar (PNAE) é uma estratégia de promoção da alimentação saudável que leva em conta o fortalecimento da economia local por meio da alimentação escolar que possui um caráter relacionado à segurança alimentar e à geração de renda para muitos municípios. O PNAE é o maior programa de alimentação escolar da América Latina, tendo em vista o tempo de atuação, a continuidade e o compromisso constitucional desde 1988. O PNAE foi pensado com o proposito de atender aos hábitos alimentares e a seus contextos sociais e é considerado uma política alimentar no Brasil, impactando o desenvolvimento econômico local por meio da aquisição de alimentos no munícipio. Com a promulgação da Lei 11.947/2009, que prevê que 30\% dos recursos do PNAE, e que determina que os agentes econômicos deem preferência aos produtores locais com recursos do FNDE. No estado de São Paulo a alimentação escolar passa a ser municipalizada, operando as compras públicas através da Lei 8.666 de 1993 (Lei das Licitações) que trabalha com a lógica de "menores custos (PAIVA 2012; GRISA; 2010).

O Programa de Aquisição de Alimentos (PAA) foi instituído em 2003 como uma das ações estratégicas do Programa Fome Zero. Criado como um instrumento de acesso aos alimentos, viabilizou a articulação entre produção e consumo adequado à realidade local e contribuiu para o fortalecimento da agricultura familiar e o desenvolvimento da economia local visando uma maior geração de renda (PAGANINI, 2010). Considera-se agricultor familiar aquele que pratica atividades no meio rural, além de não possuir área maior que quatro módulos fiscais, e que utilize mão de obra da própria família e tenha percentual mínimo da renda familiar originada de atividades econômicas do seu estabelecimento ou empreendimento. Seu reconhecimento é feito por meio da DAP, que é Declaração de Aptidão ao Programa Nacional de Fortalecimento da Agricultura Familiar PRONAF, que consiste num programa de financiamento de atividades agropecuárias e não agropecuárias, de agricultores familiares. Os créditos oferecidos podem ser para custeio (financiamento de despesas, os chamados custos variáveis, como insumos, tratos culturais, produção de mudas, sementes, mas também inclui atividades não agropecuárias); investimento (aquisição de máquinas, tratores, construção de benfeitorias nas propriedades); industrialização (agroindústria) ou integralização de cotas-partes pelos beneficiários nas cooperativas de produção agropecuária. Cota-parte é a parcela que cada agricultor tem de uma cooperativa (Banco Central do Brasil, 2020).

De tal forma que a DAP física formalizada pelo órgão emissor estadual, remete a outra providência necessária junto a Receita Federal e Junta Comercial do Estado relativa a obtenção de CNPJ, identificação de pessoa jurídica individual, para que a Nota Fiscal de produtor rural o qualifique caso responda a chamadas públicas de forma individual, como é permitido no caso 
do PNAE e várias modalidades do PAA. Tal formalização é condicionante, também, para o processo de integração em arranjos formais como Associações e Cooperativas, as quais também serão atribuídos DAP na forma jurídica, CNPJ e NF correspondentes. A falta de documentações para a obtenção da DAP por parte dos agricultores familiares com intenção de participar das vendas de seus produtos para a alimentação escolar, para atender a todas as Chamadas Públicas de Compras (CPC), das Secretarias de Educação Estaduais (SEEs) e das Secretarias Municipais de Educação (SMEs) impede a participação dos agricultores nas chamadas públicas. (Gomes \& Amorim, 2018).

O PAA compra alimentos produzidos pela agricultura familiar, tendo como finalidades precípuas promover o acesso à alimentação e incentivar a agricultura familiar. O PAA é um programa que beneficia não apenas as entidades socioassistenciais e agricultores familiares, mas toda uma rede de relações estabelecidas entre a produção e o consumo, sendo muito importante para a economia, pois promove a inclusão e aproxima sobremaneira a produção local e o público consumidor ,seja como beneficiado enquanto contingente escolar, famílias assistidas por Bancos de Alimentos, além de apontar acessos para nichos de aquisição e consumo do comércio alimentício e feiras livres de agricultura. O caminho institucional que se pavimenta para o sucesso da agricultura familiar e da geração de renda, apoia-se nas políticas públicas fomentadas pelas ações estratégicas como o Programa de Aquisição de Alimentos (PAA) e o Programa Nacional de Alimentação Escolar (PNAE), representam um grande avanço ao trazer como obrigatoriedade que ao menos $30 \%$ do investimento oferecido, conforme repasse de recurso anual do Fundo Nacional de Desenvolvimento da Educação (FNDE; 2019) aos municípios, sejam utilizados para a compra direta de alimentos provenientes da agricultura familiar, com o intuito de promover uma alimentação escolar mais saudável e com mais alimentos in natura e orgânicos adquiridos dos agricultores familiares que são critérios da seleção para as compras governamentais. (Maiellaro; et al 2020).

A aquisição pública para a alimentação escolar é um processo diferenciado que pode ser realizado com dispensa do procedimento licitatório, por meio das chamadas públicas, via compras governamentais consideradas sustentáveis, que são as aquisições que promovem fomento econômico, alimentação escolar de boa qualidade, justiça social, benefícios ambientais e de saúde para a população. As compras de alimentos provenientes da agricultura familiar, além de aproximar os agentes econômicos locais, trazem variadas potencialidades para o fortalecimento da economia local e para a valorização de uma alimentação de qualidade que respeite os hábitos alimentares, contudo, trazem diversos desafios frente à complexidade das relações entre agricultura familiar, alimentação escolar e as compras governamentais. (Assis; et al 2019).

O governo federal não interfere na gestão local, mas oferece diretrizes de como ela pode ser realizada. Resoluções de 2013 e 2015 sugerem que as formas de gestão do PNAE podem ser assim classificadas: i) centralizada, na qual órgãos governamentais recebem os recursos do FNDE, efetuam a compra de gêneros alimentícios de acordo com a legislação pertinente e distribuem para as escolas; ii) descentralizada, na qual os órgãos governamentais recebem os recursos do FNDE e efetuam a transferência para as escolas e cada uma efetua a aquisição de gêneros alimentícios perecíveis, observando a legislação específica; iii) semidescentralizada, na qual os órgãos governamentais recebem os recursos do FNDE, efetuam a compra e distribuem os gêneros alimentícios não perecíveis para as escolas e repassam parte dos recursos financeiros para que essas adquiram os produtos alimentícios. Fica claro nos três casos que a orientação do governo federal é sobre a parte financeira e a aquisição dos produtos, a tarefa de produção e entrega do serviço é local, significando que cada órgão governamental, escola, ou comunidade precisa construir sua gestão. (Brasil, 2012).

Os programas combinados de compras governamentais com vistas ao fortalecimento da economia local por meio da alimentação escolar, melhoram as condições de vida da comunidade e a qualidade da alimentação servida. Observa-se uma importante ampliação do PNAE, nos últimos anos tanto em termos de recursos financeiros e cobertura nos municípios, quanto na política pública na compra de produtos para a alimentação. 


\subsection{Economia e a Geração de renda}

A Economia é uma ciência social que estuda como o indivíduo e a sociedade decidem utilizar recursos produtivos escassos, na produção de bens e serviços, de modo a distribuí-los entre as várias pessoas e grupos da sociedade, para satisfazer necessidades humanas. É um processo sistêmico que fortalece a economia local, por meio da alimentação escolar, com o envolvimento comunitário no sistema de produção, cada fator influencia e é influenciado numa atividade de ação e reação, que sinergicamente se modificam provocando resultados.

O apoio ao fortalecimento da economia local, com a compra de alimentos da agricultura familiar, constitui importante estímulo à economia das comunidades, pois possibilita o aumento da renda dos agricultores e a melhora da qualidade dos alimentos oferecidos aos estudantes. A efetivação da compra por parte do governo proporciona mudanças no consumo de alimentos saudáveis do cardápio da alimentação escolar. Nessa questão houve maior frequência no recebimento de produtos frescos, maior variabilidade, melhor qualidade, determinando maior aceitação e consumo por parte dos alunos. (Balaban \& Peixinho, 2008; Turpin, 2008; Belik \& Souza, 2009).

Considerando a importância da alimentação escolar e seus impactos na economia local tendo em vista a segurança alimentar, busca-se fomentar as relações de consumo pautadas na solidariedade e responsabilidade. Tem-se segurança alimentar quando todas as pessoas, têm acesso físico e econômico a alimentos suficientes, seguros e nutritivos para atender às necessidades e preferências alimentares de uma vida ativa e saudável. Estender et al. (2021). A ausência de "segurança alimentar" (ou a presença de "insegurança alimentar") tem diversas causas, que merecem ser mais bem compreendidas, como, por exemplo, i) a pobreza, muitas vezes resultado de crises econômicas, aumento do desemprego e declínio dos salários, o que afeta negativamente o acesso à comida); ii a geografia (comunidades remotas falta acesso a alimentos nutritivos, variados e de qualidade); entre outros. Tais circunstancias possibilita que os agricultores familiares coloca seus produtos no mercado com maior facilidade, construindo parcerias de forma colaborativa, pois o setor rural, necessita de articulações consecutivas entre os diferentes agentes, especialmente buscando entender as necessidades nutricionais da alimentação escolar versus a produção da agricultura familiar local, para que efetivamente se promova o fomento econômico local, a inserção social dos agricultores familiares por meio da alimentação escolar.

O fluxo circular de renda é um processo sistêmico que fortalece a economia local, por meio da alimentação escolar, com o envolvimento comunitário no sistema de produção, cada fator influencia e é influenciado numa atividade de ação e reação de um fluxo contínuo, que sinergicamente se modifica, provocando resultados econômicos e contribuindo para a solução do escoamento da safra.

A produção de alimentos em escala familiar ganha destaque por se constituir em uma estratégia produtiva e de renda para os agricultores familiares, por meio da possibilidade de agregação de valor aos seus produtos, dessa forma é possível obter vantagens econômicas além de se obter maior rentabilidade e ser mais competitivo. Conforme o esquema apresentado na Figura 1: 
Figura 1: Fluxo Circular de Renda para a Alimentação Escolar.

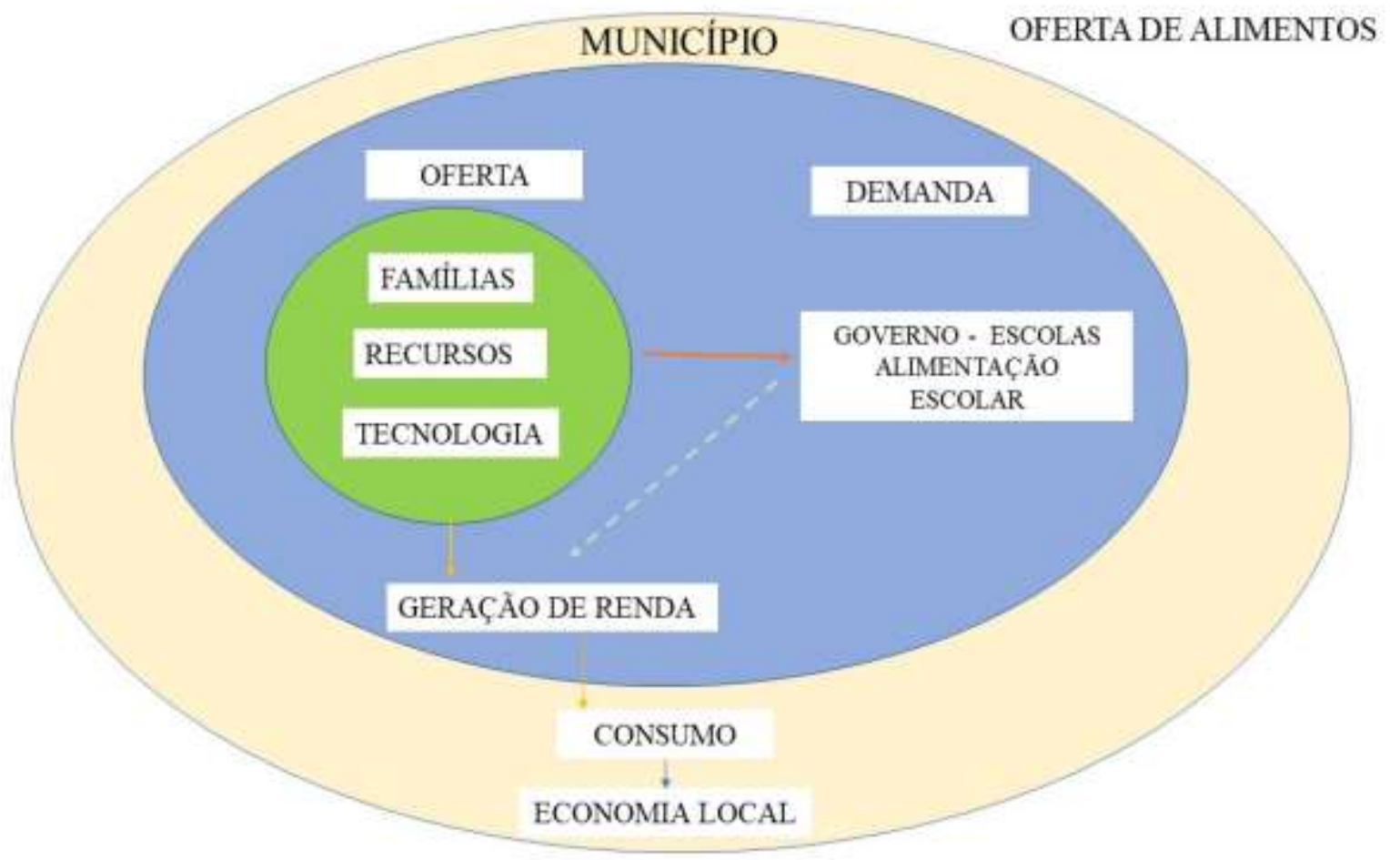

Fonte: Autores (2021).

O incentivo à economia local além de gerar renda para os agricultores alavanca outros setores econômicos e possui efeito multiplicador para o fomento da economia, trazendo impactos positivos como: i) geração de riqueza; ii) produção de alimentos; iii) mobilização dos agentes econômicos para construírem estratégias de compras governamentais; iv) promoção do fortalecimento da economia local por meio dos incentivos à produção agrícola, inclusive alterando processos de produção para oferecer um produto mais saudável aos consumidores. (Machado et al., 2018).

As compras governamentais podem auxiliar no fomento à economia local pela inserção dos pequenos agricultores familiares, especialmente em regiões menos desenvolvidas. A busca por geração de renda e pelo desenvolvimento local deve colocar os agentes econômicos no centro das preocupações com relação à geração de renda e com relação ao fomento econômico local, porém, a estratégia deve ser orientada para a ação que valoriza a produção alimentos voltados à alimentação escolar, apostando nos atores locais e na dinâmica que estimula a microeconomia, podendo ser por meio de compras públicas. Seguindo ainda a ideia de Prevost (2004), a decisão de produzir bens e serviços que já tenham uma demanda preexistente, como é o caso da alimentação escolar é uma garantia de negócios para o agricultor. A decisão por parte do governo local em comprar os bens e serviços produzidos no município, tem o propósito de fortalecer a economia local por meio da alimentação escolar.

Um trabalho árduo e contestado de esclarecimento e aceitação da dispensa licitatória foi posto em prática para a desburocratização da chamada pública com dispensa de licitação em função da Lei no 11.947 de 16/6/2009. Este papel de articulação em Itanhaém, visando a aproximação dos produtores ao Departamento de Alimentação Escolar foi capitaneado desde 2009 pelo Banco de Alimentos do município, executor do PAA modalidade CDS (compra com doação simultânea) com recursos do MC (Ministério da Cidadania) desde 2008. Há também que se registrar que os órgãos municipais citados anteriormente integravam a Secretaria Municipal de Educação, portanto as tratativas de viabilização nos trâmites legais com setores da área financeira ganharam prioridade com vistas a compra dos 30\%. No campo, a extensão ficou a cargo da parceria 
entre o Departamento da Agricultura e Pesca e a Associação dos Agricultores - AMIBRA, além da cooperação para logística, capacitação continuada e qualidade nutricional dos produtos pelo Banco de Alimentos, resultando na esperada mudança de perfil, mensurada por melhores volumes de produção e diversidade destes produtos. A desativação do funil da monocultura da banana e a garantia de acesso a comercialização com preços justos, foram fatores decisivos para consolidar um novo desenho produtivo, mais diversificado, melhorando aos poucos o acesso dos agricultores familiares às compras governamentais da agricultura familiar para a alimentação escolar. O quadro a seguir ilustra os anos de intenso trabalho de construção de mudanças no campo.

Quadro 1: Dados da chamada pública para aquisição de produto da agricultura familiar.

\begin{tabular}{|c|c|c|c|}
\hline Ano da Chamada Pública & Quantidade (kg) & Recursos & Produtos adquiridos \\
\hline 2009/2010 & 29.995 & $\mathrm{R} \$ 314.947,50$ & Banana Passa \\
\hline $2011 / 2012$ & 175.745 & $\mathrm{R} \$ 287.672,72$ & $\begin{array}{l}\text { Banana Nanica; Palmito Pupunha; } \\
\text { Maracujá; Inhame; Banana Prata } \\
\text { Couve; Chuchu. }\end{array}$ \\
\hline $2013 / 2014$ & 190.000 & $\mathrm{R} \$ 372.011,40$ & $\begin{array}{l}\text { Banana Prata; Couve; Palmito Pupunha } \\
\text { Mandioca; Tomate; Chuchu. }\end{array}$ \\
\hline $2015 / 2016$ & 108.785 & $\mathrm{R} \$ 307.672,70$ & $\begin{array}{l}\text { Cação; Robalo Pequeno; Robalo Grande; } \\
\text { Pescada Inglesa; Espada; Cenoura; Cebola; } \\
\text { Pepino; Farinha de banana verde. }\end{array}$ \\
\hline $2017 / 2018$ & 198.785 & $\mathrm{R} \$ 494.000,00$ & $\begin{array}{l}\text { Banana Nanica; Banana Prata; Palmito } \\
\text { Pupunha Banana Prata; Chuchu; Couve; } \\
\text { pescada; Farinha de Banana Verde; } \\
\text { Mandioca Processada; Alface Hidropônica } \\
\text { Tomate }\left(^{*}\right) \text {; Tangerina }\left({ }^{* *}\right) \text {. }\end{array}$ \\
\hline $2019 / \ldots$ & 208.785 & $\mathrm{R} \$ 774.214,00$ & $\begin{array}{l}\text { Couve Manteiga; Mandioca processada; } \\
\text { Banana prata; Abobrinha Italiana; Alface (lisa } \\
\text { e crespa) hidropônica; Palmito pupunha; } \\
\text { Tomate salada; Beterraba Orgânica; Repolho } \\
\text { Orgânico; Batata doce Guarani; Milho } \\
\text { Guarani. }\end{array}$ \\
\hline
\end{tabular}

(*) (**) Produtos Comprados em outro município. Fonte: Dados da PMI /Banco de Alimentos de Itanhaém (2019).

Com o propósito de propagar as informações do passo-a-passo relativas à aquisição dos produtos para a alimentação escolar, o município precisa incentivar a produção da agricultura familiar e cumprir as exigências legais de aquisição de alimentos. O diferencial, neste quesito, é a articulação e o trabalho em rede de gestores locais, para que ações conjuntas potencializem e sejam o fio condutor, tanto na composição do cardápio escolar enriquecido com informações da produção local, quanto para a real noção e segurança acerca do volume global /ano dos produtos disponíveis, as especificidades da cultura alimentar e da socio biodiversidade. Assim, atender critérios especialmente quando há PCTs (povos e comunidades tradicionais) no âmbito local e entornos, e outras especificidades que estão previstas na Resolução norteadora do PNAE, tornase de fácil entendimento e execução. Estender et al. (2021); Carvalho; et al; (2021). O CGPAE/FNDE elaborou o Manual de Aquisição de Produtos da Agricultura Familiar para a Alimentação Escolar. O passo a passo da compra governamental da agricultura familiar vincula-se à compra de gêneros alimentícios da agricultura familiar e envolve dez passos, que serão descritos a seguir: 1. levantamento dos recursos disponíveis; 2. mapeamento dos produtos da agricultura familiar; 3. elaboração do cardápio; 4. realização de pesquisa de preços para composição da chamada pública; 5. elaboração e divulgação da chamada pública; 6. elaboração do projeto de venda pelos agricultores e associações; 7. recebimento e seleção dos projetos de venda pelo município; 8. verificação da amostra para controle de qualidade dos produtos produzidos pela agricultura familiar; 9. elaboração do contrato de compra; 10. entrega dos produtos, termo de recebimento e pagamento aos agricultores familiares. 
O fornecimento de produtos para a alimentação escolar auxilia a comunidade local a ter uma renda complementar, pois o PNAE transformou-se em ferramenta de inclusão de grupos produtivos da agricultura familiar, hoje um importante acesso a geração de renda, além de contribuir sobremaneira para a melhor qualidade nutricional do prato do aluno, onde cada agricultor tem sua habilitação prioritária na cidade onde produz, com a possibilidade de atender a chamadas públicas regionais.

Precisa-se criar elos entre os agentes econômicos, identificando, conectando e fortalecendo a oferta e demanda de alimentos. Para isso, é necessário desenvolver e estabelecer canais de informação que estimulem a interação, por meio da implementação de mecanismos de comercialização para os programas de alimentação escolar.

Figura 2: Circuito econômico.

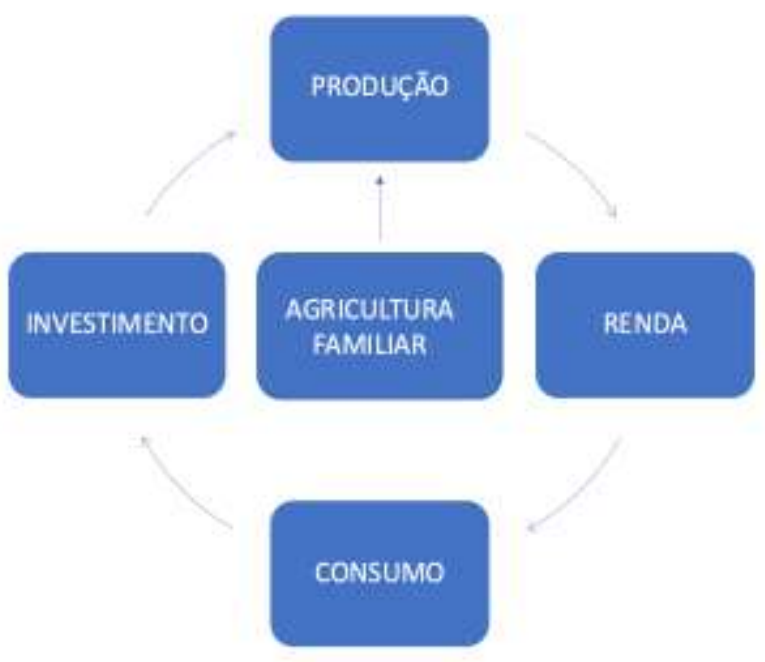

Fonte: Autores (2021).

Para que o Circuito econômico com o propósito da geração de renda se transforme em crescimento econômico local, deve haver a organização das compras governamentais por parte do poder público. A produção, renda, consumo e investimento que formam o circuito econômico incorrem em benefício para todos da comunidade local. A construção de parcerias de forma colaborativa com os agentes econômicos é fundamental, pois o setor, necessita de articulações consecutivas entre os diferentes agentes, especialmente buscando entender as necessidades nutricionais da alimentação escolar versus a produção da agricultura familiar local, para que efetivamente se promova o fomento econômico local a inserção social dos agricultores familiares por meio da alimentação escolar.

\section{Resultados e Discussão}

Os resultados descritos a seguir têm como base informações coletadas na Associação dos Produtores Rurais da Microbacia Hidrográfica do Rio Branco (AMIBRA), assim como a pesquisa exploratória realizada em visitas aos agricultores, ambas contribuíram para complementar o estudo. As discussões apresentadas buscam traduzir a interpretação dos pesquisadores, construída a partir da análise das respostas obtidas, bem como, os dados obtidos a partir da observação in loco.

Os gestores municipais se basearam em características locais e regionais que favoreceram a produção de alimentos, buscou-se diversificar os alimentos e produtores, o que privilegiou a produção de diversos outros produtos que são utilizados na alimentação escolar. Com essa prática houve um crescimento exponencial da produção de alimentos e outros produtores 
iniciaram suas atividades com vistas ao fornecimento de alimentos para a alimentação escolar da região. $\mathrm{O}$ engajamento de novos produtores na região também contribuiu para o crescimento da renda e da produção de pequenos produtores, porém, é importante ressaltar que os agricultores precisam se organizar por meio de alguma associação de agricultores local para poderem participar das compras governamentais e usufruírem dos benefícios oferecidos por elas. As compras governamentais incentivam a diversificação na produção de alimentos para atender a demanda do município e promover o fortalecimento da economia local, propiciando novas alternativas de comercialização da produção e melhorando a qualidade de vida da comunidade.

O governo federal repassa aos municípios valores financeiros em 10 parcelas mensais (de fevereiro a novembro) para cobrir 200 dias letivos, conforme o número de alunos matriculados em cada modalidade de ensino. A lei brasileira 11.947 garante que 30\% do valor repassado pelo PNAE seja aplicado na compra direta de produtos da agricultura familiar. A lei estimula o fortalecimento econômico por meio da alimentação escolar. (FNDE, 2018). O Estado atua como regulador e provedor da alimentação escolar e o cálculo para o repasse governamental é obtido pela fórmula VT = A x D x C - na qual VT = Valor a ser transferido pelo FNDE; $\mathrm{A}=$ Número de alunos; $\mathrm{D}=$ Número de dias atendidos; $\mathrm{C}=$ Valor per capita para aquisição de alimentos.

Tabela 1 - Valor de repasse financeiro diário por aluno.

\begin{tabular}{l|c}
\hline \multicolumn{1}{|c|}{ MODALIDADE DE ENSINO } & Reais \\
\hline Creches & 1,07 \\
\hline Pré-escola & 0,53 \\
\hline Escolas indígenas e quilombolas & 0,64 \\
\hline Ensino fundamental e médio & 0,36 \\
\hline Educação de jovens e adultos & 0,32 \\
\hline Ensino integral & 1,07 \\
\hline Programa de fomento as escolas de ensino médio em tempo integral & 2,00 \\
\hline Alunos do atendimento educacional especializado & 0,53 \\
\hline
\end{tabular}

Fonte: Com base em FNDE (2019c).

Pode-se observar no quadro acima como se constitui a verba destinada pelo governo federal, montante esse calculado pelo número de alunos matriculados em cada uma das modalidades de ensino. A proporção de participação das esferas governamentais é de aproximadamente um terço da verba destinada a alimentação escolar pelo governo federal por meio do PNAE e os outros dois terços são compostos pelos governos estaduais e municipais. A iniciativa privada e a sociedade civil contribuem de forma esporádica e sem nenhum compromisso legal.

O Fundo Nacional de Desenvolvimento da Educação (FNDE) não transfere recursos financeiros do PNAE diretamente às escolas. Os repasses são transferidos às secretarias estaduais de educação e prefeituras. O programa é fiscalizado pelos Conselhos de Alimentação Escolar (CAE), além de órgãos de controle, como Tribunal de Contas da União (TCU), Controladoria Geral da União (CGU) e o Ministério Público. A Resolução no 38, de julho de 2009 do FNDE, alterada pela Resolução/CD/FNDE n ${ }^{\circ}$ 26, de 17 de junho de 2013, veio garantir aos agricultores uma nova oportunidade, pois a partir desta, os estados e municípios têm a "obrigação" de comprar a produção de alimentos dos agricultores locais. Tal fato torna os agricultores detentores de exclusividade frente ao mercado local de hortifrutigranjeiros, pescados, entre outros.

Para que o município saiba o valor financeiro que receberá anualmente, para cada modalidade, deverá multiplicar o número de alunos declarados no censo escolar do ano anterior pelo valor per capta estabelecido e pelo número de dias letivos, conforme a fórmula acima descrita. 
Uma gama de atividades de apoio à agricultura familiar destinada a melhorar o fornecimento de alimentos dos pequenos agricultores tem sido de suma importância para os agentes econômicos e para tanto o PNAE e o PAA são essenciais para a implantação de programas de aquisição de alimentos da agricultura familiar. As dificuldades operacionais limitam o ritmo das compras governamentais para a alimentação escolar e para que possam funcionar de forma adequada é necessário promover a articulação entre os agentes econômicos e as demandas locais de alimentação, resultando no fortalecimento da economia local, na geração de trabalho/renda no campo e na comunidade, pois os agricultores são também consumidores locais. (Lopes; Diniz.; 2018).

Figura 3: Comunidade de agricultores.

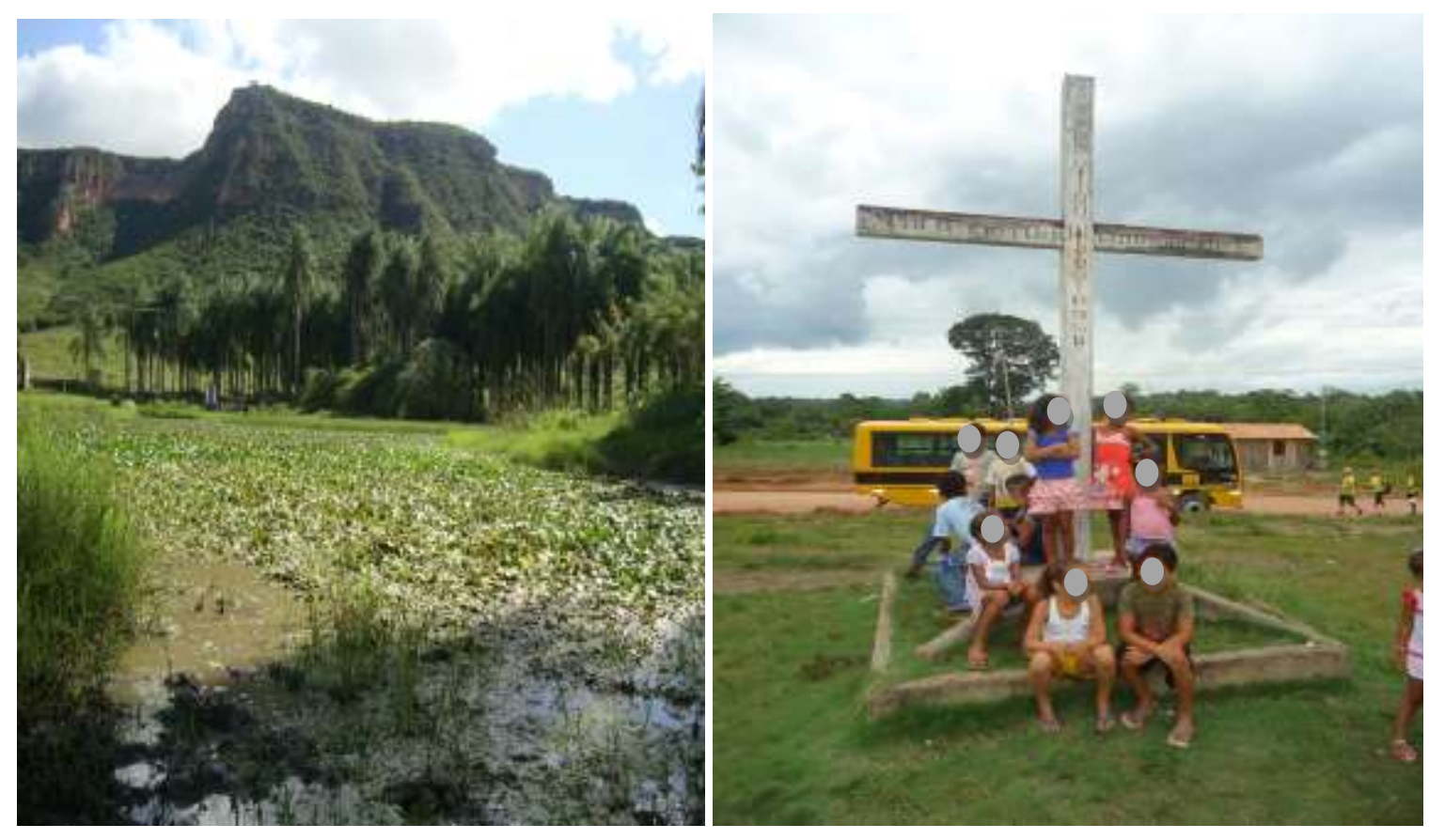

Fonte: Autores (2021).

Os recursos investidos em compras governamentais da agricultura familiar no escopo do PNAE, e do PAA, provocam efeitos econômicos intersetoriais e impactos positivos nos PIBs dos municípios. A articulação entre os agentes econômicos: governo, associações e a comunidade promove o fortalecimento da economia local, gerando renda na comunidade, porém, devem se organizar para a efetivação e a contribuição tanto para o fortalecimento da economia local, como para o fornecimento de refeições da alimentação escolar que atendam aos princípios de uma alimentação saudável e adequada, contribuindo também para a diminuição da pobreza na comunidade. 
Tabela 2: Gêneros alimentícios produzidos para a alimentação escolar.

\begin{tabular}{c|l|c|c|c}
\hline Item & \multicolumn{1}{|c|}{ Produto } & $\begin{array}{c}\text { Quantidade } \\
\text { em Kg }\end{array}$ & $\begin{array}{c}\text { Unidade } \\
\text { R } \$\end{array}$ & $\begin{array}{c}\text { Total } \\
\text { R } \$\end{array}$ \\
\hline 1 & Banana prata & 77.375 & 3,91 & $302.497,15$ \\
\hline 2 & Alface (lisa e crespa). & 13.000 & 6,96 & $90.480,00$ \\
\hline 3 & Mandioca processada & 10.950 & 4,99 & $54.640,50$ \\
\hline 4 & Palmito pupunha & 12.300 & 17,38 & $213.774,00$ \\
\hline 5 & Batata doce & 850 & 3,43 & $2.915,50$ \\
\hline 6 & Beterraba orgânica & 6.000 & 4,53 & $27.180,00$ \\
\hline 7 & Repolho orgânico & 5.000 & 4,19 & $20.950,00$ \\
\hline 8 & Milho guarani & 146 & 8,25 & $1.204,50$ \\
\hline 9 & Batata doce guarani & 300 & 3,43 & $1.029,00$ \\
\hline 10 & Mandioca tradicional guarani & 260 & 4,16 & $1.081,60$ \\
\hline
\end{tabular}

Fonte: Autores (2021).

Os alimentos provenientes da agricultura familiar para a alimentação escolar podem contribuir tanto para o desenvolvimento econômico local como para o fornecimento aos escolares de refeições que atendam aos princípios de uma alimentação saudável e adequada. O valor total dos recursos destinados à aquisição de gêneros alimentícios da Agricultura Familiar para merenda escolar do exercício de 2019 foi de $\mathrm{R} \$ 715.779,83$ (setecentos e quinze mil e setecentos e setenta e nove reais e oitenta e três centavos). O preço de aquisição é o preço a ser pago ao fornecedor da agricultura familiar. (Resolução FNDE 06/2020, Art.31, §4º. A Compra de Gêneros Alimentícios da Agricultura Familiar para Alimentação Escolar.

A importância do processo de diversificação da produção de alimentos, segundo Ellis (1998), é decorrente da relação entre as atividades agrícolas e comerciais. Essa questão surge quando se observa que o desenvolvimento agrícola estimula as atividades não-agrícolas, e cresce de tal forma, que os recursos decorrentes das compras governamentais induzem transformações na agricultura.

O crescimento do Brasil passa pela agricultura familiar. O agricultor familiar tem grande importância para o crescimento do país. De acordo com o último Censo Agropecuário, a agricultura familiar é a base da economia de $90 \%$ dos municípios brasileiros com até 20 mil habitantes. Além disso, é responsável pela renda de 40\% da população economicamente ativa do País e por mais de 70\% dos brasileiros ocupados no campo. De acordo com o Ministério do Desenvolvimento Agrário (MDA) mostra que a agricultura familiar tem um papel predominante para a economia. Com um faturamento anual de US\$ 55,2 bilhões, mesmo que o Brasil tivesse apenas a produção familiar, ainda assim estaria entre os 10 maiores produtores de alimentos do mundo. Os dados fazem parte de uma comparação entre dados do Banco Mundial e do Ministério da Agricultura, Pecuária e Abastecimento. Ao somarmos a agricultura familiar com toda a produção, o país passa de oitavo maior para a quinta posição, com faturamento de aproximadamente US\$ 85 bi por ano. (Brasil, 2018).

\section{Considerações Finais}

Os resultados demonstram que é necessária a articulação entre os agentes econômicos: governo, associações e a comunidade, buscando entender as necessidades de produção da agricultura familiar e de consumo de alimentos nas escolas, para que efetivamente atinja-se o objetivo deste artigo que é entender a alimentação escolar via compras governamentais e o 
aumento da renda dos agricultores familiares, contribuindo para fortalecer a microeconomia do município, contribuindo para alavancar a microeconomia do município. Favorecendo o envolvimento comunitário no sistema de produção tendo como base o Programa Nacional de Alimentação Escolar (PNAE).

Promover a organização dos pequenos produtores é fundamental para a melhoria da produção local de alimentos voltados para a alimentação escolar, fortalecendo a renda dos produtores, que podem causar mudanças econômicas na comunidade, impactando o comércio local por meio de uma maior geração de empregos e do desenvolvimento da agricultura familiar com vistas à melhoria da alimentação escolar. Quando se conecta os pequenos negócios e serviços com a sociedade, melhora-se a renda da população, facilitando a vida de todos, pois os envolvidos no processo da alimentação escolar, ou seja, os agricultores familiares produzindo os alimentos do cardápio das escolas e o governo, que por sua vez, oferece programas de alimentação consegue encontrar os produtos necessários no munícipio, oferecendo apoio aos pequenos produtores que fazem a ponte entre a demanda e a oferta com negociação rápida e direta, gerando-se uma cadeia curta de fornecedores mais rápida e eficiente com a qual todos ganham, pois os recursos financeiros ficam na região, retornando para o município em forma de saúde, educação e benefícios sociais.

Assis et al (2019) ponderam que, se por um lado, a compra governamental de alimentos provenientes da agricultura familiar além de aproximar os agentes econômicos locais, traz variadas potencialidades para o fortalecimento da economia local e para a valorização de uma alimentação de qualidade que respeite os hábitos alimentares, por outro, traz diversos desafios frente à complexidade das relações entre agricultura familiar, alimentação escolar e as compras governamentais. Um ponto a ser destacado é sobre as compras governamentais que geram renda e têm influência na arrecadação de impostos. Municípios com potencial agrícola e com acesso aos fundos governamentais como o PNAE e o PAA podem incrementar a alimentação escolar gerando renda na comunidade, fortalecendo a economia de tal forma que conduza a consolidação de um sistema agroalimentar local (SIAL).

O que se verificou é que o PNAE e o PAA são necessários para aumentar a renda dos agricultores, pois alguns fatores agregam valor aos produtos produzidos: a possibilidade de ter uma cozinha industrial e o beneficiamento de alguns produtos que aliados a um sistema de transporte adequado, melhoram a rentabilidade e, consequentemente, a sua comercialização. $\mathrm{O}$ PNAE tem sido instrumento de fomento à economia, promoção social e geração de renda, porém deve ser articulado de forma harmônica entre os agentes econômicos, para que todas as dimensões da segurança alimentar nutricional sejam atendidas através destas políticas públicas. A organização e gestão dos recursos públicos aplicados para a compra governamental de produtos agrícolas para a alimentação escolar não é uma tarefa das mais fáceis pela própria estrutura do processo licitatório.

Dessa forma, na identificação e análise dos resultados relatados que compõem o segmento de alimentação escolar, verificou-se que muitos são os desafios para se promover ações que fortaleçam uma política pública inovadora e saudável que traga retornos para a sociedade; priorizem políticas públicas com grande efeito multiplicador na renda das famílias, comunidades e do poder público deve ser o caminho a ser seguido.

Diante do exposto, a luz da teoria pesquisada, da apuração e análise dos resultados apresentados, as principais contribuições desse artigo foram: i) Compras governamentais se bem conduzidas podem fortalecer a economia local; ii) enfatizar a importância da necessidade de analisar e apoiar novas formas de comercialização dos produtos no município e, gerar renda local por meio de compras governamentais; iii) Ficar atento à relação entre políticas públicas; alimentação escolar e consumo, produção de alimentos por meio do Programa de Alimentação Escolar (PNAE).

Dada a relevância do tema, como proposta de estudos futuros recomenda-se identificar as principais sugestões que surgiram na elaboração do artigo como por exemplo: o fomento à acessibilidade aos alimentos com vistas à redução da insegurança alimentar; a otimização das cadeias curtas de distribuição e, por fim, a diminuição do desperdício de alimentos no preparo da alimentação escolar. 


\section{Agradecimentos}

Este estudo foi financiado em parte pela Coordenação de Aperfeiçoamento de Pessoal Ensino Superior - Brasil (CAPES) - Código Financeiro 001.

\section{Referências}

Assis, T. R. P., Franca, A. G. M., \& Coelho, A. M. (2019). Agricultura familiar e alimentação escolar: desafios para o acesso aos mercados institucionais em três municípios mineiros. Rev. Econ. Sociol. Rural, 57(4), 577-593.

Balaban D. S., \& Peixinho A. (2008). Ten key elements for the introduction of sustainable national programs.

Brasil (2012a). Lei $\mathrm{n}^{\mathrm{o}} 11.326$ de 24 de julho de 2006. Estabelece as diretrizes para a formulação da Política Nacional da Agricultura Familiar e Empreendimentos Familiares Rurais (on-line). http://www.planalto.gov.br/ ccivil_03/_ato2004-2006/lei/111326.htm.

Brasil. (2012). Ministério Da Educação. Fundo Nacional de Desenvolvimento da Educação. Resolução/CD/FNDE n. 2/2012. Estabelece orientações, critérios e procedimentos para a utilização obrigatória a partir de 2012 do Sistema de Gestão de Prestação de Contas (SiGPC), desenvolvido pelo FNDE para a gestão do processo de prestação de contas.

Brasil. (2019). Fundo Nacional De Desenvolvimento Da Educação - FNDE. Programa Nacional de Alimentação Escolar - PNAE. Histórico [Internet]. Brasília: Ministério da Educação, [citado em 2021 Jun 2021]. Disponível em:https://www.fnde.gov.br/programas/pnae/pnae-sobre-o-programa/pnae-historico. https://www.fnde.gov.br/programas/pnae/pnae-sobre-o-programa/pnae-historico.

Carnevalli, D. B. A. (2017). Efeito da Lei Federal 11.947/09 na qualidade nutricional dos cardápios propostos pelo Programa de Alimentação Escolar do estado de São Paulo (text). Universidade de São Paulo. https://doi.org/10.11606/D.6.2017.tde-01082017-143518.

Carvalho, G. C. G., Morais, I. B. de A., Oliveira, G. A. L. de, \& Vendrametto, O. (2021). Family farming and school feeding: reflections of the COVID-19 pandemic. Research, Society and Development, 10(4), e13910413911. https://doi.org/10.33448/rsd-v10i4.13911.

Chauhan, A. (2015). Plates for slates: The impact of a school feeding programme on community representations of schools. International Journal of Educational.

Condon, E. M., Crepinsek, M. K., \& Fox, M. K. (2009). School Meals: Types of Foods Offered to and Consumed by Children at Lunch and Breakfast. Journal of the American Dietetic Development, 41(Supplement C), 292-300.

Estender, A. C.: et al. (2021a). Fortalecimento da economia local por meio da alimentação escolar proveniente da agricultura familiar. Foz do Iguaçu. Encontro Nacional de Engenharia de Produção. ENEGEP.

Estender, A. C., dos Santos, N. A., Agio, J. L. D., Ruggero, S. M., Souza, A. E., \& Vendrametto, O. (2021b) Strengthening Local Economy through School Feeding. In: Asia Pacific Conference on Industrial Engineering and Operations Management. Surakarta, Indonésia

FNDE, A. D. C. S. D. (2018). Dados Físicos e Financeiros do PNAE - Portal do FNDE. URL: http://www.fnde.gov.br/programas/pnae/pnae-consultas/pnaedados-fisicos-e-financeiros-do-pnae.

FNDE, N.E.D.F.: (2019). National school feeding program - PNAE, https://www.fnde. gov.br/programas/PNAE.

Glewwe, P. (2005). The impact of child health and nutrition one education in developing countries: Theory, econometric issues, and recent empirical evidence. Food and Nutrition Bulletin, 26(2), S235-S250.

Gomes, S. A. B., \& Amorim, L. B. de. (2019). Agricultura Familiar: importância e dificuldades da inserção na alimentação escolar na microrregião de Picos PI. Pesquisa Agro, 1(1), 39-48. https://doi.org/10.33912/AGRO.2596-0644.2018.v1.n1.p39-48.id253.

Grisa, C. (2010). As redes e as instituições do Programa de Aquisição de Alimentos (PAA). Revista Brasileira de Gestão e Desenvolvimento Regional, 6(2), 97-129.https://doi.org/10.1016/j.ijedudev.2014.07.013.

Jomaa, L. H., Mcdonnell, E., \& Probart, C. (2011). School feeding programs in developing countries: impacts on children's health and educational outcomes. Nutrition Reviews, 69(2), 83-98. https://doi.org/10.1111/j.1753-4887.2010.00369.x.

Kristjansson, E. A., Gelli, A., Welch, V., Greenhalgh, T., Liberato, S., Francis, D., \& Espejo, F. (2016). Costs, and cost-outcome of school feeding programmes and feeding programmes for young children. Evidence and recommendations. International Journal of Educational Development, 48(Supplement C), 79-83. https://doi.org/10.1016/j.ijedudev.2015.11.011.

Lopes, S. R. S., \& Diniz, P. R. (2018). Boas práticas de agricultura familiar para a alimentação escolar / Programa Nacional de Alimentação Escolar. Technical Report Ministério da Educação/Fundo Nacional para o Desenvolvimento Escolar Brasília. URL: ile:///C:/Users/Jo \%C3\%A 3o\%20R\%20Maiellaro/Downloads/Boas\%20Prticas\%20de\%20agricultura\%20familiar\%20 para\%20a\%20alimentao\%20escolar\%20DIGITAL.pdf.

López-Olmedo, N., Jiménez-Aguilar, A., Morales-Ruan, M. Del C., Hernández-Ávila, M., Shamah-Levy, T., \& Rivera-Dommarco, J. A. (2018). Consumption of foods and beverages in elementary schools: Results of the implementation of the general guidelines for foods 179 and beverages sales in elementary schools in Mexico, stages II and III. Evaluation and Program Planning, 66(Supplement C), 1-6. https://doi.org/10.1016/j.evalprogplan.2017.08.009.

Machado, G. C. X. M. P., Maciel, T. M. F. B., \& Thiollent, M. (2018). Uma metodologia de pesquisa-ação integral e sistêmica para saneamento em cogestão com comunitários tradicionais, aplicada na Comunidade Caiçara da Praia do Sono. In: ACTION RESEARCH NETWORK OF THE AMERICAS CONFERENCE, 5., 2017, Cartagena. Proceedings... San Diego: Arna. 〈Disponível em: http://bit.ly/3rDWcX0 >. 
Research, Society and Development, v. 10, n. 15, e270101522863, 2021

(CC BY 4.0) | ISSN 2525-3409 | DOI: http://dx.doi.org/10.33448/rsd-v10i15.22863

Mcewan, P. J. (2013). The impact of Chile's school feeding program on education outcomes. Economics of Education Review, 32, 122-139. https://doi.org/10.1016/j.econedurev.2012.08.006.

Mészáros, I. (2011a). Para além do capital. Rumo a uma teoria de transição. Boitempo.

Nogueira, R. M., Barone, B., Barros, T. T. DE, Guimarães, K. R. L. S. L. de Q., Rodrigues, N. S. S., Behrens, J. H., \& Behrens, J. H. (2016). Sixty years of the National Food Program in 180 Brazil. Revista de Nutrição, 29(2), 253-267. https://doi.org/10.1590/1678-98652016000200009.

Paganini, S. A. (2010). implantação do PAA. In: MDS. Fome Zero Uma História Brasileira. editora I-Comunicação.

Paiva, J. B. de, Freitas, M. do C. S. de e Santos, L. A. da S. (2012). Hábitos alimentares regionais no Programa Nacional de Alimentação Escolar: um estudo qualitativo em um município do sertão da Bahia, Brasil. Rev. Nutr \{online\}. http://www.dx.doi.org/10.1590/S1415-52732012000200002 http://www.dx.doi.org/10.1590/S1415-52732012000200002.

Triches R. M., \& Schneider, S. (2010). Alimentação escolar e agricultura familiar: reconectando o consumo à produção. Saúde Soc. 2010,19(4):933-45. » http://dx.doi.org/10.1590/S0104-12902010000400019.

Triches, R. M. (2010). Reconectando a Produção ao Consumo: a aquisição de gêneros alimentícios da agricultura familiar para o Programa de Alimentação Escolar. Tese (Doutorado em Desenvolvimento Econômico) - Universidade Federal do Rio Grande do Sul, Porto Alegre.

Yin, R. K. (2014). Estudo de caso: planejamento e métodos. Tradutor: Daniel Grassi. (2a ed.), Bookman. 